\title{
Legal Issues Concerning P2P Exchange of Educational Materials and Their Impact on E- Learning Multi-Agent Systems
}

\author{
Eugenio Gil and Andrés G. Castillo Sanz, \\ University Pontificial of Salamanca, Madrid Campus, Spain
}

\begin{abstract}
The last years have known an impressive change in the use of technologies for the sharing and dissemination of knowledge, thus affecting deeply all the traditional means used by education in all its shapes and levels. This transformation has not been fully understood by the society at large for its immense impacts and its short life. This paper describes in the question emerging from the clash of the rights to education in a wide sense and the rights derived from authorship and how that issue is affecting the design of e-learning multi-agent tools.
\end{abstract}

Keywords - Education, Law, Multi-agent Systems for eLearning, Intelligent Knowledge Sharing

\section{INTRODUCTION}

$\mathrm{I}^{\mathrm{n}}$ $\mathrm{n}$ the last years we have fully entered in a social

environment generally known as Information and

Knowledge Society (IKS), which is essentially characterized in that it is a society that is largely driven by technology and technological advances that occur almost daily.

This new society which we refer to has received over recent years different names such as Cibersociety or Networked Society [5], but it is from a legal point of view that a greater uniformity has been achieved in the sense that both the different agencies of the European Union and those of Spain have preferred to use a broader concept such as the Information Society when legislating, which leads to the concept mentioned above of the Information and Knowledge Society, taking into account what Professor Davara [3] affirms, that information is an element that gives great power to its owners already from the beginning of time, emerging therefore a class of people: the owners of information.

It's not enough to own pieces of information, it is mandatory to know how to look for it and how to handle it, it becoming stronger who knows better how to handle with it, it being an asset which does not get exhausted with their consumption but it is enriched instead by its being used. This allows that its expansion is taking place with the creation of more information by means of the development of telecommunication systems.

This concept of information should be put in touch with another concept that has been widely used in recent years under the context of the Information Society, such as it is that of Knowledge, because the latter is no more than stored information, which is preserved and treated by its recipients the same, i.e. the people.

The study of this IKS begun already in the late nineteensixties and early 70's by various thinkers. Those studies were consolidated in the two decades following the 80 and 90, in which a key event took place in the development IKS too, such as the emergence of the PC. In recent years of present decade, the expansion of the IKS has been so voracious by means of the monstrous development of computer technology that have led the personal, social, economic and cultural relationships to be influenced to a greater or lesser extent by such information technologies or information technologies.

No field of knowledge, from economics to law, have been untouched by this technology boom, including of course the field of Education, whose study we will address here, although we will be analyzing in it from a legal point of view the impact that it is produced by the emergence of different technologies. All this has given rise to what some authors have called Information Processing and Digital Competence, that is, the skills that a student should have acquired by the end of their educational years and which involves being more than a simple user of ICT. It involves being an autonomous, efficient, responsible, critical and reflective person at the time of processing, selecting, and using the information, its sources and its supporting media [7].

Teaching is no longer just a platform through which the teacher discloses his knowledge using lectures as it was the case until recently. It has become an area in which both the teacher and the student form an inseparable element, through which they are jointly engaged in the task of teaching and learning both connected via ICT, whose mastering brings about the possibility of using them as a tool for searching, processing, communication ... in short, as a basic tool for knowledge acquisition. This is how the concept of digital natives emerges, as persons who are characterized by the following [4]:

They receive information quickly

They like to work in parallel and multitasking

They prefer images to text

They prefer random access 
They work best when they work in a network

They thrive on instant gratification and frequent rewards They prefer to play games than to work seriously

At this point we must highlight a key element for the development of digital natives, that is, the emergence, consolidation and development of Internet usage (essential piece of the new Information Society), which has caused a transformation unimaginable a few years ago in the customs of students in their academic habits. The digital text analysis, the search of online resources or the monitoring of teaching through virtual campuses have become hallmarks of our society that has led us in many cases to a delocalization of the University, the student has access to it at any time and from any place she wishes to.

Apparently the new digital world in which we live offers many advantages in education, and certainly so, but we should not forget to keep in mind that misused technology can cause major problems especially in regard to the effects that it may have in the fundamental rights of the people.

An instrument that offers many possibilities is file sharing networks. These networks allow users to exchange information and documentation so that they disseminate what we have previously called Knowledge. It seems clear that from an educational point of view we may encounter tools that have immense potential. The problem arises at the moment that technology allows us to perform (via these networks) file sharing (e.g. textbooks or reference books) that are protected by intellectual property rights. At this point we should question if these networks are a valid tool in education since access to culture is above the right of the author, or if on the contrary we should curtail the use of them (in the case we just find the a mechanism to do so).

\section{But what are these file sharing networks?}

At the end of the decade of the 90s emerged the so-called peer to peer $(\mathrm{P} 2 \mathrm{P})$ or networks among friends or individuals. It is a network that allows the exchange of information among peers which has had an extraordinary boom with the advent of the Internet and that is closely linked with the MP3 format. The MP3 is simply a format for data compression, a standard developed by the Fraunhofer Institute in 1987, with which you get that a minute of music with quality similar to an audio CD occupies only a megabyte, reducing its size by about 12 times [8].

At present P2P networks operate as a decentralized network that has neither fixed clients nor servers, but it has a number of nodes that behave simultaneously as both clients and servers of the other nodes in the network. The emergence of these networks has been opposed not only by the authors of these works and holders of intellectual property rights, but also of the Managing Entities of Intellectual Property Rights, which argue the great losses suffered by the industry as a result of these actions. In contrast to the detractors of the use of these networks is an important part of Internet users who postulate the law as fundamental argument that everybody should have free access to culture and knowledge, and the necessary adaptation of the legal rules to the new possibilities offered by technology.

One of the first cases of P2P was Napster. It was a file download program created by Shawn Fanning, a student of Computer Science in 1999. Its main problem was that it had a centralized directory from which could be known both existing files on the computers of users and the members that were online. A user accessed the directory, and if the requested file was there and the user who had it was connected, the download proceeded. The existence of this directory or central server provided the basis for considering that it was breaking the rules on copyright, and in July 2001 a U.S. judge ordered the closure of Napster servers. If Napster was closed primarily by the existence of a central server, the goal was clear: to provide the same service as Napster through a decentralized network. Thus numerous programs were created that managed to achieve this purpose: KaZaA, eDonkey, Morpheus, eMule, etc. [1]. They obviously omitted to use a central server and all computers connected to the system functioned simultaneously as both clients and servers, that way as new users download the software, the network grows exponentially.

The emergence of these networks allows the enjoyment of music or books for free (although they have many more utilities such as sharing and file search, internet telephony systems, scientific computing to process large databases, etc..) , and it has been opposed not only by the authors of these works and holders of intellectual property rights on them, who have seen it as an element giving away the result of their work for free in breach of current legislation intellectual property, but also of the Managing Entities of intellectual property Rights, which argued the heavy losses suffered by the sector as a result of these actions, and that has made recently in the month of May 2009 that a class action from several management institutions against Pablo Soto Bravo was filed in Spain as the creator of a number of P2P programs (Blubster, Piolet and Manolito [6]) on the grounds that it violates the rules of intellectual property and claiming a significant compensation for damages. Without delving further into this matter, it should be noted that one thing is that the file download behavior may constitute a crime, and another one is that the software that allows such activity must be given the same consideration, which in principle is difficult to share with the claimants of the aforementioned process.

The 'case Soto' started in June 2008 when, for civil proceedings, the recording industry, represented by Promusicae, Warner, Universal, EMI and Sony sued the software developer of Pablo Soto for 13 million euro in damages, for they considered that his programs Blubster, Piolet and ManolitoP2P were developed under the MP2P protocol, and that they were intended for illegal sharing of copyrighted music between individuals. Recently, the final decision in this case acquitted Pablo Soto considering that no 
offense was committed.

\section{SANCTIONABLE BEHAVIORS?}

We have certainly made ourselves this question more than once, when we download a book for following a study subject or simply a reference book. Of course if we make the download paying the amounts that we are required, this download will be perfectly legal, but if we do it through a file sharing network which I accessed through a links page to? Do I commit any offense? What can happen to me? And what about the administrator of website who hosts the links page?

The answer to be given is that nothing can happen to us, or at least that was the situation we were before the famous socalled Sinde Law. And I say nothing on the grounds that I shall try to summarize below.

In the Spanish legal system the possibilities for action against the user or against the administrator of the site is focused on two areas, criminal matters (for the commission of a crime) or civil (for the infringement of a right arising damages, in this case the author's rights).

\section{THE CRIMINAL SCOPE}

In criminal cases the starting point is the first paragraph of Article 270 of the penal code, which states: "It shall be punished with imprisonment from six months to two years and a fine of 12 to 24 months who, for financial gain and to the detriment of third, reproduce, plagiarize, distribute or communicate publicly, in whole or in part, a literary, artistic or scientific work or processing, interpretation or performance fixed in any medium or communicated by any means without the consent of the holders of the relevant intellectual property rights or assigns."

The debate in this area focuses on the existence of profit in file downloading behavior, because if it did not exist, such conduct hardly could be criminalized.

It seems clear that when a person downloads a book through a P2P network, he gets something that somehow could match that profit, because of the fact that it saves the money it would cost that product on the market. Traditionally the doctrine and the courts have been considering that profit amounts to obtaining any benefit, advantage or utility 2 as a result of an activity, so that the mentioned savings could be considered comparable to profit. However, this concept of profit has been developed mainly in the field of criminal offenses against property (robbery, theft, fraud, misappropriation ...) in which it is easier to appreciate and value the gain, and it should not be applicable to those behaviors in which the new tools offered by technology play a key role.

In short, the application of Article 270 of the penal code to the conduct described in the absence of profit would be at least against two basic principles that should govern international penal matters, on one hand the principle of minimum intervention of the criminal law according to which latter

\footnotetext{
${ }^{2}$ Judgment of the Supreme Court of Spain of March 25, 2004.
}

should act only in cases of extraordinary gravity and where imposed sanctions are the most severe, and on the other hand the principle of proportionality, clearly perverted if we consider the different sanction which involves a minor theft of a music $\mathrm{CD}$ in front of downloading that $\mathrm{CD}$ through the mentioned networks (imprisonment under Article 270 of the Spanish penal Code). This position has been followed also by Spanish courts, which have chosen not to include these offenses in Article 270 in the absence of the subjective element of profit. Thus, the Court of Cantabria3 on appeal and, in a supposed Internet download of exact copies of music albums, has held that the defendant's conduct is atypical and therefore not criminally punishable when it had not been proved that he acted with trading profit because he did not collect nor was enriched beyond his personal savings.

The Court of Cantabria takes upon itself a concept of commercial profit that had been used two years ago by the Attorney General's Office's Circular 1/2006, understanding it as a form of profit and thus giving rise to an interpretation of profit in strict sense. In this sense, the memo cited is very enlightening to note that the alleged violation of rights should be relegated to the realm of civil violations in which the purpose of obtaining some advantage or benefit other than commercial may be implicit.

At the same time we must keep in mind that if we access the file sharing network through a page of links, the links page itself is not committing any criminal offence it does not perform the objective behaviour that describes the aforementioned Article 270 since they do not distribute or reproduce or publicly communicate the files, simply because they do not have them. What it does is to allow us to access the network exchange from which in turn we access the files, this conduct does not constitute a crime in our penal code. The Spanish courts have stated so in various resolutions, as it could be illustrated in the Order of July 2, 2009 the Commerce Court of Barcelona and the Order of November 13, 2009 of the Commerce Court of Huelva.

\section{THE CIVIL SCOPE}

Having abandoned the criminal procedure it should be considered the possibility of acting in civil proceedings against the users of these networks as a result of the infringement of copyright and therefore in their case demanding compensation for damages.

Within the general rights that are recognized to the authors and leaving aside moral rights (for its unalienable4 nature), it is important to emphasize that among the exploitation rights is fundamentally one which can be inflicted by users of these networks, such as the right of reproduction and also as the case that of public communication.

The regulation of the reproduction right is located in Article 18 of the Spanish TRLPI which qualifies it as "direct or indirect, temporary or permanent fixation by any means and in

\footnotetext{
${ }^{3}$ Judgment of the Court of Cantabria of February 18, 2008.
} 
any form of the whole work or part thereof, which makes possible its communication or the production of copies."

In relation to the injury of this right of reproduction whose ownership belongs to the author, there seems no doubt as to those websites that facilitate the direct download of books. Certainly there would be major problems with the downloading activity performed by users of P2P networks, basically for two reasons, firstly the difficulties regarding their identification and secondly the possible inclusion of the downloading activity in any of limiting or exception assumptions collected by the Spanish Law of Intellectual Property.

The first proposed assumption, such as the downloading of files directly through a web, was treated by the Barcelona Provincial Court in its judgment of September 29, 2006, which condemned to compensation for damages to the owner of www.redmp3.com and www.servidormp3.com websites for infringement of intellectual property rights by carrying out acts of reproduction and making works available without permission, that judgment stating that reproducing a work is " incorporating and attaching it into a physical hardware that enables communication and production of copies of all or part of the work." "que queda incluido en el concepto de reproducción la carga y almacenamiento de material digitalizado en la memoria muerta de un ordenador u otro sistema o aparato electrónico que lo retenga de modo estable; de modo que cuando se digitaliza una obra y se fija en un medio que permita su comunicación y la obtención de copias, se ejecuta un acto de reproducción5". Thus, based on Article 9.1 of the Berne Convention which refers that the playback can be performed under any procedure or any form, the abovementioned judgment concludes "that it is included in the concept of reproduction the download and storing of digitized material in the ROM of a computer or other electronic device system which stably holds it, so that when a work is digitalized and fixed in a medium that makes possible its communication and the obtaining of copies, it occurs an act of playback6 ".

In relation to the second mentioned case, the identification of users, it is necessary to know who are the people doing the aforementioned downloads, or in this case the holders of the IP addresses from which such downloads are made, so as to direct against them the corresponding actions. This work of identification encounters many obstacles, mainly derivatives of the right to secrecy of communications and the right to

\footnotetext{
${ }_{5}^{4}$ Article 14 of the Spanish Law of Intellectual Property 1996.

5 The above considerations led to the conclusion that the defendant has committed an act of reproduction invading the sphere of the author in accordance with the provisions of articles 17 et seq. of Intellectual Property Law, Article 11 of the WIPO Treaty on December 20, 1996 and Article 2 of Directive 2001/29/EC on the harmonization of certain aspects of copyright, thus corresponding compensation of damages.

${ }^{6}$ The above considerations led to the conclusion that the defendant has committed an act of reproduction invading the sphere of the author in accordance with the provisions of articles 17 et seq. of Intellectual Property Law, Article 11 of the WIPO Treaty on December 20, 1996 and Article 2 of Directive 2001/29/EC on the harmonization of certain aspects of copyright, thus corresponding compensation of damages.
}

privacy, regulated both in almost all modern constitutional texts, where constant reference is made to the necessary judicial intervention required to act against this right, a judicial intervention which does not occur because the absence of crime (as we saw in the previous section). The judges put before the right to privacy of the user against the prejudice caused to the author

Whereupon and in short, we face a situation in which the performance of file download of books or music through a filesharing network does not constitute a criminal offence, and therefore the courts do not allow to take action against users based on their right to privacy (thus excluding them also against civil proceedings). But common sense seems to indicate that this reproduction activity injures or impairs the right of someone (the author) who should somehow be protected.

\section{V.THE SINDE LAW}

In the area of the European Union it has been sought to advance in this matter through the creation of new laws, and in this regard a French Law was approved in May, known as Hadopi law, which permits to disconnect from the Internet those users who persist in downloading files after being warned twice through an ad hoc set up body such as the High Authority for the Dissemination of Works and Protection of Rights on the Internet. Contested this law before the French Advisory Council (a body similar to our Constitutional Court), this one has shown to be contrary to it by saying that if it is true that a sanction should be imposed if the existence of illegal downloads is discovered (which seems logical and which is covered by this Council by means of limiting thus the right to privacy of the users), also points out that this High Authority is not competent to impose the penalty, since only a judge may order the cut of the connection to potential offenders.

In similar terms the European Parliament has recently manifested in a report on September 2011, but later and surprisingly on November 5 of that year it changed its position authorizing such disconnections without prior judicial authorization while referring to some concepts that we believe will lead us in any case to the necessary involvement of a judge. The European Parliament states that in order to avoid abuses in the restrictions, they "may only be imposed if they are appropriate, proportionate and necessary for a democratic society," then stating that "we must respect the presumption of innocence and the right to privacy".

In the Spanish case and given the impossibility to act against users, there has been raised in our legal system the possibility of closing the pages of links that provide access to exchange networks for the users. In order to achieve this aim, the socalled Sinde Law have been developed, changing through the Draft Law on Sustainable Economy the Services Information Society and Electronic Commerce Act in its Article 8, establishing the possibility of closing by an organ belonging to 
the Ministry of Culture those websites that violate intellectual property rights as set out in point 4.4 of the First Final Provision of the said Draft.

This law has been developed through the RD 1898/2011 of 30 December. It has been a very controversial and widely criticized regulation by users the Internet.

Without wishing to dwell on the specific rules governing this regulation, we believe that the main problem that frames the norm is the attribution to an administrative body such as the 2nd Section of the Copyright Commission to decide whether there has been or not a breach of the copyright. This brings us to cases in which a judge has considered that there is no offence in a specific conduct, while this Commission believes otherwise.

After the appearance of the first voices against this lack of legal certainty, there was given a new formulation to the regulation itself now introducing the necessary judicial intervention in two moments. Firstly to ask the intermediary service provider to identify the owner of the links service provider, if not known, and secondly to allow or not the measure of closing the links page which has been taken by the Commission. It is the second case which continues to pose the greatest problems, because the judge's decision will not be determined by the assessment of whether or not there is infringement, because he or she is not allowed get into assessing the facts in deep [2]. He can only pronounce on the implementation of the measure by analyzing the proportionality between the infringement of the intellectual property rights and the rights of Article 20 of the Constitution which may be affected due to the closure of the page, essentially the freedom of expression and the seizure of publications.

\section{IMPACT ON MAS}

It is well known that the success of multi-agent systems is largely linked with the solution of security problems associated with its use. The autonomous character of agent behavior implies that the users that give them important tasks must trust them with confidential data. The design of the system must ensure that no other person or agent can access illegally the data carried by the owner's agent [13]. Whereas organizational agents are confronted with general security risks of networkoriented applications, the adoption of open and mobile agents in e-learning tasks introduces a new dimension.

The aforementioned legal issues concerning the downloading of educational material from $\mathrm{p} 2 \mathrm{p}$ networks and links pages add a new level of complexity to the design of multi-agent systems which would be able to help students in their tasks [9].

In our prototype e-learning multi-agent system we have added one ontology [10] for the agents to know and learn when a links page is legally reliable, and an ancillary agent role which autonomously questions the explorer agents and web search applications to keep a register of sure pages updated.
Every student is encouraged to keep a repository of downloaded educational materials, such as books, shorter documents, databases, images, videos, audio files, etc... in which the copyright issues can be legally certified [12]. We think that if the tools provided are used to search and bring back that material for everywhere on the Internet, the students would agree to a reasonable degree of control on legal materials.

\section{CONCLUSIONS AND FUTURE WORK}

On top of unresolved security problems affecting multiagent systems, the design of multi-agent systems as e-learning tools has encountered the new educational landscape created along with the tremendous explosion of educational (multimedia and every other type) at the disposal of students. Form childhood on every student counts on the possibility of getting every imaginable document at a few clicks of distance. Mobile or navigational agents are the perfect tool for facilitating the students the task of search and retrieving of knowledge in any form [11]. We should make our agents more copyright-violation conscious than our students likely will be. We are therefore including that ability from the very beginning of their design.

\section{REFERENCES}

[1] J. P. Aparicio Vaquero, El intercambio de archivos en redes de pares a la luz del derecho vigente. En: Revista Aranzadi de Derecho y Nuevas Tecnologías No.8. Madrid. pp. 55-72 2005. ISSN: 1696-0351.

[2] J. Carbonel, Josep; M. Sabates, La controvertida Disposición Final Cuadragésimo Tercera: "Ley Sinde". Madrid: Economist \& Jurist (150), 2011 pp. 26-31.

[3] M. A. Davara Rodríguez, Manual de Derecho Informático. Madrid: Aranzadi, p.23. ISBN: 84-9767-018-3, 2001.

[4] A. Fumero, Jóvenes e Infotecnologías. Madrid: Instituto de la Juventud, Ministerio de Sanidad, Política Social e Igualdad, 2012, p.17.

[5] L. Joyanes, Cibersociedad. Madrid: McGraw-Hill. p.4 ISBN: 84-4810943-0, 1997.

[6] R. J. Millán Tejedor, Domine las Redes P2P. Madrid: Creaciones Copyright S.L. p.234. ISBN: 84-96300-20-X, 2006.

[7] A. Perez Sanz,Escuela 2.0. Educación para el mundo digital. Madrid: Instituto de la Juventud, Ministerio de Sanidad, Política Social e Igualdad (92) 2011, pp.63,86.

[8] L. J. Rodríguez Baena, Luis José, Transmisión de la cultura en la era digital. Tesis Doctoral (Doctor en Ciencias Políticas y Sociología.). Madrid: Universidad Pontificia de Salamanca. Facultad de Ciencias Políticas y Sociología, 2001 p. 206.

[9] P. A. Rodríguez, V. Tabares, N. D. Duque, D. A. Ovalle, and R. M. Vicari, "BROA: An agent-based model to recommend relevant Learning Objects from Repository Federations adapted to learner profile", in International Journal of Interactive Multimedia and Artificial Intelligence, Vol. 2, March 2013, pp. 6-11.

[10] G. A. Isaza, A. G. Castillo, M. López, L. F. Castillo, M. López, "Intrusion Correlation Using Ontologies and Multi-agent Systems", In proceeding of: Information Security and Assurance - 4th International Conference, ISA 2010, Miyazaki, Japan, June 23-25, 2010. Proceedings 01/2010; pp.51-63.

[11] J. C. Fernandez-Rodriguez, J. Rainer, and F. Miralles-Muñoz, "Engineering Education through eLearning technology in Spain", in International Journal of Interactive Multimedia and Artificial Intelligence, Vol. 2, March 2013, pp. 46-50.

[12] Y. Villuendas-Rey, C. Rey-Benguría, Y. Caballero-Mota, and M. M. García-Lorenzo, "Improving the family orientation process in Cuban 
Special Schools trough Nearest Prototype classification", in International Journal of Interactive Multimedia and Artificial Intelligence, Vol. 2, March 2013, pp. 12-22.

[13] G. Isaza, A. Castillo, M. López, L. Castillo, "Towards Ontology-Based Intelligent Model for Intrusion Detection and Prevention", Computational Intelligence in Security for Information Systems Advances in Intelligent and Soft Computing Volume 63, Springer, 2009, pp 109-116 (Book Chapter).

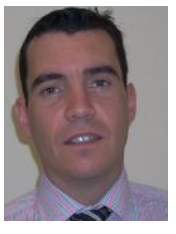

Eugenio Gil López. Born in Galicia (Spain) in 1972. He has a degree in Law from Deusto University in Spain. He is researcher in Pontifical University of Salamanca in the field of Laws in Information Technologies and Master of Laws Thesis Option. Actually he is Academic Secretary at the School of Engineering and Architecture in Pontifical University of Salamanca, Madrid campus.

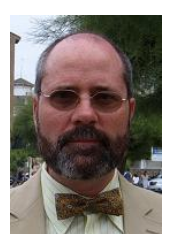

Andrés G. Castillo Sanz Born in Madrid in 1964. He has degrees in Physics, Sociology and Theology from the Complutense University of Madrid. The doctoral degree was obtained in 2004 at the Pontificial Unversity of Salamanca. $\mathrm{He}$ is researcher in that University mainly in the field of applied multiagent systems. He also participates in several research groups on different Universities in Spain and other European countries. 